into the study. The project was supported by a generous grant (No. G970/211/C) from the Medical Research Council.

Requests for reprints should be addressed to Dr. R. H. R. White.

\author{
References \\ 1 Guttman, D., and Naylor, G. R. E., British Medical fournal, 1967, 3, 343. \\ 2 Arneil, G. C., McAllister, T. A., and Kay, P., Lancet, 1970, 1, 119. \\ 3 Scherstén, B., and Fritz., H., fournal of the American Medical Association, \\ 1967, 201, 949. \\ ${ }^{4}$ Scherstén, B., and Tibbling, G., Clinical Chemistry, 1968, 14, 243. \\ 5 Scherstén, B., et al., fournal of the American Medical Association, 1968, \\ 204, 113. \\ 6 Savage, D. C. L., et al., British Medical fournal, 1969, 3, 75. \\ 7 Huttunen, N.-P., Mella, E., and Mäkelä, R., Lancet, 1970, 1, 22 \\ ${ }^{8}$ Cheyney, P., and Whitehead, T. P., personal communication, 1970. \\ ${ }^{9}$ McAllister, T. A., et al., Nephron, 1973, 11, 111.
}

10 Walten, M. G., and Kunin, C. M., Fournal of Pediatrics, 1971, 78, 246. 1 Rolleston, G. L., Shannon, F. T., and Utley, W. L. F., British Medical Fournal, 1970, 1, 460.

${ }^{12}$ Köhler, L., Fritz, H., and Scherstén, B., Acta Paediatrica Scandinavica, $1972,61,289$.

${ }^{13}$ Emmerson, A. M., fournal of Obstetrics and Gynaecology of the British Commonwealth, 1972, 79, 828 .

14 Dosa, S., et al., Archives of Disease in Childhood, 1973, 48, 733.

15 McKinnon, A. E., et al., British fournal of Urology, 1974, 46, 101.

${ }_{16}$ Meadow, S. R., White, R. H. R., and Johnston, N. M., British Medical Fournal, 1969, 3, 81. R. H. R., and Johnston, N. M., British
Kunin, C. M., New England Fournal of Medicine, 1970, 282, 1443.

17 Kunin, C. M., New England Fournal of Medicine, 1970, 28

18 Braude, H., et al., British Medical fournal, 1967, 4, 702.

Kunin, C. M., Southall, I., and Paquin, A. J., New England Fournal of Medicino, 1962, 266, 1287.

20 Savage, D. C. L., et al., Archives of Disease in Childhood, 1973, 48, 8.

21 Asscher, A. W., et al., Lancet, 1973, 2, 1.

22 Parsons, V., et al., Clinical Nephrology, 1974, 2, 179.

23 Bailey, R. R., Clinical Nephrology, 1973, 1, 132.

24 Rolleston, G. L., Maling, T. M. J., and Hodson, C. J., Archives of Disease in Childhood, 1974, 49, 531 .

25 Davies, et al., Lancet, 1974, 2, 7 .

\title{
Immune Status of Children with and without Severe Infection during Remission of Malignant Disease
}

\author{
J. GRAHAM-POLE, M. L. N. WILLOUGHBY, S. AITKEN, A. FERGUSON
}

British Medical fournal, 1975, 2, 467-470

\begin{abstract}
Summary
The immune status of children with malignant disease in remission was assessed using various immune function tests. Children with infections had significantly more neutropenia, hypogammaglobulinaemia, and impaired cell-mediated immune responses than those without. These two groups combined had much more absolute lymphopenia and impairment of both cell-mediated immunity and antibody-producing capacity than control children with non-malignant conditions. Regular immunological evaluation is recommended for children with malignant disease when new intensive treatment schedules are under trial and for individual patients particularly prone to develop infections during treatment.
\end{abstract}

\section{Introduction}

In the last 10 years an aggressive therapeutic approach has radically altered the prognosis for children with acute leukaemia and other malignant diseases. ${ }^{12}$ Though such treatment produces long remissions its immunosuppressive effects make children susceptible to opportunistic infections with organisms of low pathogenicity. ${ }^{3}{ }^{4}$ Such infections endanger life as much as the severe bacterial infections which occur in relapses but are associated with different patterns of immunological disturbance. The malignant process also may impair a child's immunity. Leucopenia, ${ }^{5}$ diminished antibody production, ${ }^{6}$ and impaired cell-mediated responses $^{78}$ all increase the child's susceptibility to infection.

University Department of Child Health and Department of Haematology, Royal Hospital for Sick Children, Glasgow G3 8SJ

J. GRAHAM-POLE, M.R.C.P., D.C.H., Lecturer in Child Health

M. L. N. WILLOUGHBY, M.D., M.R.C.PATH., Consultant Haematologist

University Department of Bacteriology and Immunology, Western Infirmary, Glasgow G11 GNT

S. AITKEN, B.SC., Research Assistant

A. FERGUSON, M.R.C.PATH., PH.D., Lecturer in Immunology (Present address: Western General Hospital, Edinburgh 4)
We investigated the immune status of children receiving cytotoxic treatment during remission of malignancy and compared them with normal children and children with malignant disease before treatment or after completing protracted treatment. We aimed to define the type and extent of immune defect and how it differs during infections and what tests might predict those at particular risk of infection.

\section{Patients}

The 56 children studied included 36 with leukaemia and other malignant diseases and 20 controls most of whom were poorly thriving and had had recurrent pneumonia, sepsis, or enteric infections, for which no underlying cause was apparent (table I). The children with malignancies suffered the following 14 infections: bronchopneumonia (probably non-bacterial) (3 cases), pneumocystis pneumonia (3), herpes zoster (3), measles and pneumonia (2), candidiasis (2), and cytomegalovirus infection (1). Some children were tested more than once during the study and all the results were analysed.

\section{Methods}

We assessed cell-mediated immunity by peripheral blood lymphocyte counts, tuberculin $1 / 100$ or $1 / 1000$ skin tests, and lymphocyte culture with non-specific mitogens and specific antigens. Neutrophil production was measured by neutrophil count. Humoral immunity was measured by serum immunoglobulins and titres of several antibacterial and antiviral antibodies. The percentage of non-thymic dependent B-lymphocytes was measured in some patients. Many children had low neutrophil and lymphocyte counts, which made certain tests impossible.

For white blood counts $1 \mathrm{ml}$ blood was anticoagulated with EDTA. Total white cell counts were performed with a Coulter counter and differential counts of 100 cells with Leishman's stained smears. The rest of the blood was separated by centrifuge over a gradient of 24 parts $9 \% \mathrm{w} / \mathrm{v}$ Ficoll (Pharmacia) to 10 parts $34 \% \mathrm{w} / \mathrm{v}$ Triosil 440 (Nyeguard and Co., Oslo). It was layered over the solution after sterilizing by millipore filtration in a 3:2 Ficoll : blood ratio. The gradient was spun at $400 \mathrm{~g}$ at $4{ }^{\circ} \mathrm{C}$ and lymphocytes aspirated from the plasma/Triosil interface. The plasma was assayed for (a) IgG, IgA, and IgM by single radial immunodiffusion, using Hoechst tripartigen plates and immunoglobulin standard; $(b)$ bacterial agglutinins with disposable microtitre trays (Flow Labs), using bacteroides, proteus, and Escherichia coli isolated in pure culture from human faecal and 
TABLE I-Details of Patients Studied and Numbers of Investigations Performed at Various Stages of Treatment

\begin{tabular}{|c|c|c|c|c|c|c|c|}
\hline & & & A.L.L. & A.M.L. & Lymphoma & Neuroblastoma & Controls \\
\hline $\begin{array}{l}\text { No. of patients } \\
\text { Mean age (years) } \\
\text { No. of investigations } \\
\text { Before treatment } \\
\text { During treatment } \\
\text { On well children } \\
\text { On infected children } \\
\text { After treatment }\end{array}$ & $\begin{array}{l}\cdots \\
\cdots \\
\cdots \\
\cdots \\
\cdots\end{array}$ & $\begin{array}{l}\ldots \\
\cdots \\
\cdots \\
\cdots \\
\cdots\end{array}$ & $\begin{array}{r}5 \\
9 \\
15 \\
5\end{array}$ & $\begin{array}{l}2 \\
5 \cdot 2 \\
3\end{array}$ & $\begin{array}{l}5 \\
7 \cdot 8 \\
9\end{array}$ & $\begin{array}{l}2 \\
1 \\
2 \\
0\end{array}$ & $\begin{array}{l}20 \\
3 \cdot 7 \\
20\end{array}$ \\
\hline
\end{tabular}

A.L.L. = Acute lymphoblastic leukaemia.
A.M.L. = Acute myeloblastic leukaemia.

TABLE II-Abnormal Results of Tests in Different Groups of Children. Results are Numbers of Abnormal Results out of Numbers of Tests Performed. Significances of Difference from Controls are Given

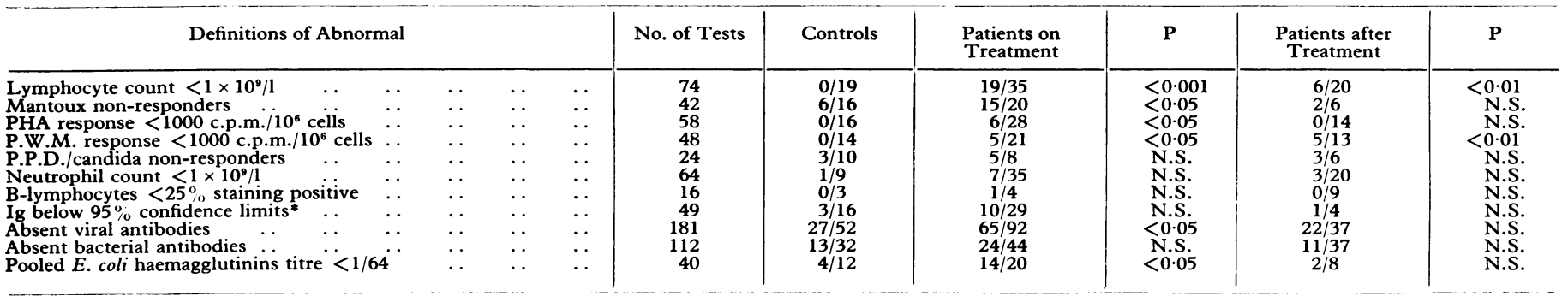

*IgA, IgG, and IgM below $95 \%$ confidence limits for age. ${ }^{24}$

urine specimens and a reference culture of Salmonella adelaide. Haemagglutinins were also assayed against pooled $E$. coli serotypes $;^{9}$ and $(c)$ antiviral antibodies against herpes/varicella, measles, poliovirus 2 , and cytomegalovirus. Preinfected "spots" of $10^{3}$ Vero tissue culture cells were dispensed with trypsin-versene mixture, centrifuged, and resuspended in phosphate buffered saline (P.B.S.). Eight $50-\mu 1$ spots were dispensed on to each glass slide and antibodies titrated by indirect immunofluorescence with serial dilution of each serum sample from $1 / 2$ to $1 / 256$ for 30 minutes at $37^{\circ} \mathrm{C}$. After washing in P.B.S. they were secondarily stained with fluorescein-conjugated rabbit antihuman IgA using naphthalene black TG $(1 \mathrm{mg} / \mathrm{ml}$ conjugate), and antibody titres were read on a Reichelt Zetopan fluorescence microscope.

\section{LYMPHOCYTE CULTURE}

The buffy layer was washed twice in Eagle's Minimal Essential Medium (M.E.M.) Glasgow modification (with penicillin and streptomycin). Lymphocyte counts were adjusted to give $10^{6}$ cells $/ \mathrm{ml}$ in a medium of $10 \%$ heat-inactivated fetal calf serum, $2 \%$ HEPES buffer (Flow Labs), $0.13 \%$ sodium bicarbonate, and M.E.M. without bicarbonate. The cells were cultured in sterile tissue culture grade microtitre plates with flat-bottomed wells, containing $2 \times 10^{5}$ $(0.2 \mathrm{ml})$ for each mitogen or antigen tested. These were placed in $10-\mathrm{ml}$ volumes in a moist $37^{\circ} \mathrm{C}$ chamber in a $5 \%-\mathrm{CO}_{2}$ atmosphere.

Mitogens used were: phytohaemagglutinin (PHA, Wellcome) at a final dilution 1/10; pokeweed mitogen (P.W.M., Grand Island Biological Co.) at a dilution $1 / 5$; tuberculin purified protein derivative (P.P.D., Evans Medical Ltd.) at a fināl dilution $100 \mathrm{U} / \mathrm{ml}$; and Candida albicans (Bencard) at a final dilution 1/10. One set of wells had no additions and the mitogen concentrations used were those giving optimal responses with normal adult lymphocytes. Mitogen cultures were incubated for three days and specific antigens for five days $;^{14} \mathrm{C}$-thymidine $(0.2 \mu \mathrm{Ci} /$ well $)$ was added for the last four hours and isotope uptake measured by the millipore assay technique. ${ }^{10} \mathrm{Cell}$ suspensions were extracted with $10 \%$ trichloroacetic acid and $2 \mathrm{ml}$ absolute alcohol and filter papers dried in air. Radioactivity was measured in a Packard Tri-carb liquid scintillation counter and expressed as counts per minute (c.p.m.) $/ 10^{6}$ cells. The value of tubes with no mitogen was subtracted from the mean value of triplicate tubes containing mitogens. Lymphocyte stimulation was also assessed by morphological examination of cytocentrifuge preparations stained with Leishman's stain.

\section{ANALYSIS OF RESULTS}

Mean lymphocyte and neutrophil counts and PHA and P.W.M. responses in each group were compared by Students' $t$ test. Results were also grouped according to whether they were positive or negative or above or below an arbitrary dividing point between low and normal (see table II).

\section{EFFECT OF TREATMENT}

The effects of treatment on results were assessed as follows. Patients who had had only one or two oral maintenance drugs in the past 10 weeks - such as 6-mercaptopurine (6MP), methotrexate (MTX), or cyclophosphamide (CPM) - were compared with those who had had at least four drugs, including two or more of the following: prednisolone (PRED), vincristine (VCR), adriamycin (ADR), daunorubicin (DNR), cytarabine (CTA), asparaginase (colaspase), or high-dosage CPM (300-600 $\mathrm{mg} / \mathrm{m}^{2}$ intravenously); patients who had had only cranial or no radiotherapy were compared with those who had had craniospinal radiotherapy for prophylaxis or treatment.

Patients with acute lymphoblastic leukaemia (A.L.L.) were on one of the following drug schedules: M.R.C. UKALL I, ${ }^{11}$ II, or III; cyclic chemotherapy ${ }^{12}$; or protocol 6801 of acute leukaemia group B. ${ }^{13}$ All remissions were induced with PRED and VCR plus colaspase or DNR in some, and treatment continued with $6 \mathrm{MP}$ and MTX, with "pulses" of VCR and PRED every one, three, or six months. Low-dosage oral CPM $\left(75 \mathrm{mg} / \mathrm{m}^{2}\right)$ was included in the cyclic schedule, and some children on UKALL schedules had high-dosage CPM $\left(600 \mathrm{mg} / \mathrm{m}^{2}\right)$, colaspase, ADR, DNR, and CTA. Four patients with lymphoma were induced with VCR, ADR, and CPM weekly $(\times 6)$, and maintained on oral 6MP, MTX, and CPM. The fifth was on a more intensive six-drug schedule. Two patients with A.L.L. were on TRAMPCOL. ${ }^{14}$ The patients with neuroblastoma had combined VCR, ADR, and CPM intravenously each week plus, in one case, oral procarbazine.

Twelve patients had had craniospinal radiotherapy 2500 rads a mean of 20 months earlier, 11 had had cranial radiotherapy rads 2500 plus intrathecal MTX a mean of six months before, and 13, mainly those with lymphoma or neuroblastoma, had had no rodiotherapy.

\section{Results}

Immune Function.-Table II shows the number of abnormal results in different groups. Patients on treatment had significantly more lymphopenia, negative Mantoux test reselts, and low mitogenic responses than controls, and lymphopenia and impaired P.W.M responses were still commoner after treatment (table II). Mean lymphocyte counts and P.W.M. responses were significantly lower both during and after treatment (figs. 1 and 2), while mean PHA response was significantly lower only in infected patients (fig. 3). 
TABLE III-Proportion of Abnormal Results $\dagger$ and Mean Values on Different Types of Treatment

\begin{tabular}{|c|c|c|c|c|c|c|c|c|}
\hline & & \multirow{2}{*}{\multicolumn{2}{|c|}{ 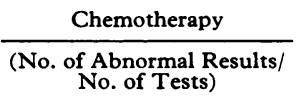 }} & \multicolumn{5}{|c|}{ Radiotherapy } \\
\hline & & & & \multicolumn{2}{|c|}{ Craniospinal } & \multicolumn{2}{|c|}{ None or Cranial } & \multirow{2}{*}{$\begin{array}{c}\stackrel{P}{P} \\
\text { (for Mean } \\
\text { Values) }\end{array}$} \\
\hline & & Intensive & Maintenance & $\begin{array}{l}\text { Mean Values } \\
( \pm \text { S.D. })\end{array}$ & $\begin{array}{c}\text { No. of Abnormal } \\
\text { Results/No. of } \\
\text { Tests }\end{array}$ & $\begin{array}{l}\text { Mean Values } \\
( \pm \text { S.D. })\end{array}$ & $\begin{array}{c}\text { No. of Abnormal } \\
\text { Results/No. of } \\
\text { Tests }\end{array}$ & \\
\hline $\begin{array}{l}\text { Lymphocytes }\left(\times 10^{9} / 1\right) \\
\text { Neutrophils }\left(\times 10^{\circ} / 1\right) \\
\text { PHA response } \log \left(\text { c.p.m. } / 10^{8} \text { cells }\right) \\
\text { P.W.M. } \\
\text { I. W. response } \log \text { (c.p.m. } / 10^{6} \text { cells) } \\
\text { Ig below } 95 \% \text { confidence limits } \quad \ldots\end{array}$ & $\begin{array}{ll}\cdots & \cdots \\
\cdots & \cdots \\
\cdots & \cdots \\
\cdots & \cdots\end{array}$ & $\begin{array}{r}19 / 28 \\
7 / 28 \\
6 / 22 \\
4 / 15 \\
10 / 26\end{array}$ & $\begin{array}{l}0 / 7^{*} \\
0 / 7 \\
0 / 6 \\
1 / 6 \\
0 / 7^{* *}\end{array}$ & $\begin{array}{l}1.069 \pm 0.919 \\
3.064 \pm 1.522 \\
2.561 \pm 1.467 \\
1.900 \pm 1.69\end{array}$ & $\begin{array}{r}13 / 19 \\
1 / 18 \\
4 / 15 \\
5 / 11\end{array}$ & $\begin{array}{l}1 \cdot 261 \pm 0 \cdot 824 \\
2 \cdot 758 \pm 1 \cdot 705 \\
3 \cdot 614 \pm 0.464 \\
3 \cdot 071 \pm 1 \cdot 624\end{array}$ & $\begin{array}{l}8 / 23^{* * *} \\
6 / 23 \\
2 / 18 \\
5 / 17\end{array}$ & $\begin{array}{l}\text { N.S. } \\
\text { N.S. } \\
<0.01 \\
<0.01\end{array}$ \\
\hline
\end{tabular}

* Intensive $v$. maintenance chemotherapy, $\mathrm{P}<0.001$.

**Intensive $v$. maintenance chemotherapy, $P<0.05$.

*** Craniospinal $v$. none or cranial radiotherapy, $P<0.05$.

TABLE IV-Mean Values and Proportion of Abnormal Results* in Infected and Well Patients on Treatment

\begin{tabular}{|c|c|c|c|c|c|c|c|c|}
\hline & & & & \multicolumn{2}{|c|}{ Well Patients } & \multicolumn{3}{|c|}{ Infected Patients } \\
\hline & & & & $\begin{array}{l}\text { Mean Values } \\
( \pm \text { S.D. })\end{array}$ & $\begin{array}{c}\text { No. of Abnormal } \\
\text { Results/No. of Tests }\end{array}$ & $\begin{array}{l}\text { Mean Values } \\
( \pm \text { S.D. })\end{array}$ & $\begin{array}{l}\text { No. of Abnormal } \\
\text { Results/No. of Tests }\end{array}$ & $\begin{array}{c}\mathbf{P} \\
\text { (for Mean } \\
\text { Values) }\end{array}$ \\
\hline 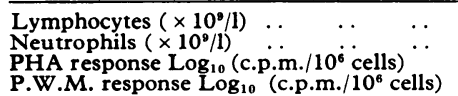 & $\begin{array}{l}. \\
\cdots \\
\cdots\end{array}$ & $\begin{array}{l}. \\
\cdots \\
\ldots\end{array}$ & $\begin{array}{l}\cdots \\
\cdots \\
\cdots\end{array}$ & $\begin{array}{l}1.011 \pm 0.867 \\
3.267 \pm 1.730 \\
3.611 \pm 0.312 \\
3.005 \pm 1.170\end{array}$ & $\begin{array}{r}12 / 21 \\
2 / 21 \\
2 / 15 \\
1 / 13\end{array}$ & $\begin{array}{l}0.975 \pm 0.747 \\
1.917 \pm 1.281 \\
2.543 \pm 1.655 \\
1.393 \pm 0.637\end{array}$ & $\begin{array}{l}7 / 14 \\
7 / 14 \\
4 / 13 \\
4 / 8\end{array}$ & $\begin{array}{l}\text { N.S. } \\
<0.002 \\
<0.001 \\
<0.001\end{array}$ \\
\hline
\end{tabular}

*See table II for definitions of abnormal for each value.

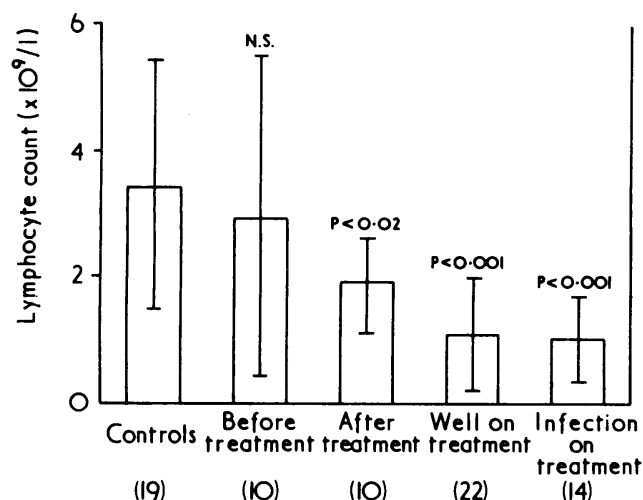

FIG. 1-Lymphocyte counts in different groups. In this and figs. $2-4$ horizontal bars represent means \pm S.D. number of determinations in each group is shown in parentheses, and $P=$ significance of difference from controls.

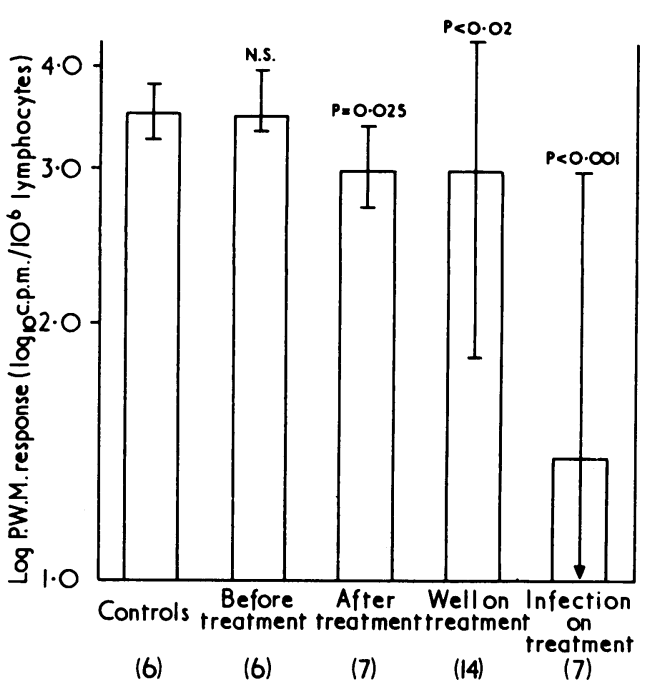

FIG. 2- $\log _{10}$ P.W.M. response in different groups.
Neutropenia was slightly commoner in patients on treatment than in controls, while mean neutrophil counts were significantly lower in untreated patients and those on treatment, particularly those with infections (fig. 4). Negative antibody titres to viruses and pooled $E$. coli antigens were significantly commoner in patients on treatment than in controls (table II), and hypogammaglobulinaemia was also slightly commoner in treated patients. No differences were recorded for the tests of lymphocyte surface immunofluorescence or the other antibacterial antibodies tested.

Influence of Treatment.-Significantly more patients were lymphopenic after recent intensive chemotherapy or craniospinal radiotherapy (table II). Neutropenia, poorer mitogenic responses, and hypogammaglobulinaemia were almost confined to the intensive therapy group, while mean PHA and P.W.M. responses were significantly lower after craniospinal radiotherapy than after cranial or no radiotherapy. All the infected children had had recent intensive chemotherapy while a third of the well patients were on oral maintenance drugs only. Previous radiotherapy had no influence on the presence of infection.

Differences in Immune Status between Infected and Well Patients.Clear differences were seen between patients with infections and those without (table IV). Though there were no significant differences in numbers of abnormal results infected children had significantly lower mean neutrophil counts and PHA and P.W.M. responses than well patients. Though neither mean lymphocyte count nor frequency of lymphopenia differed significantly over $50^{\circ} \%$ of all children treated were lymphopenic when tested.

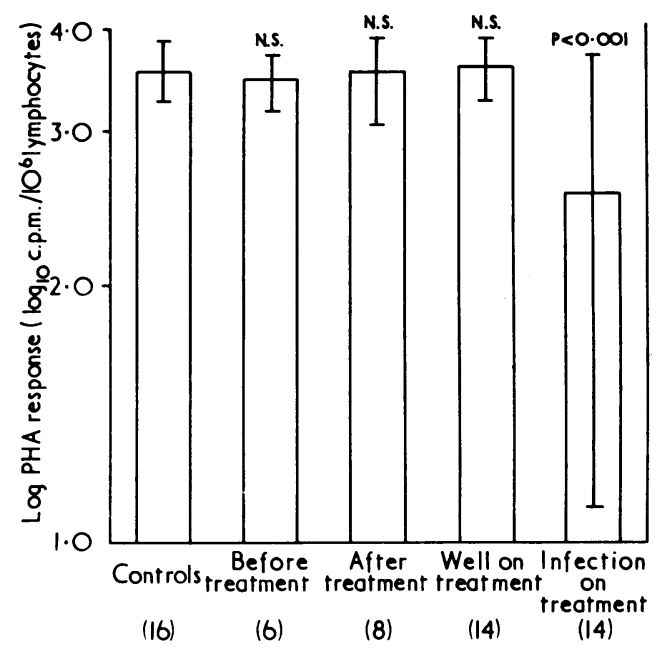

FIG. 3- $\log _{10}$ PHA response in different groups. 


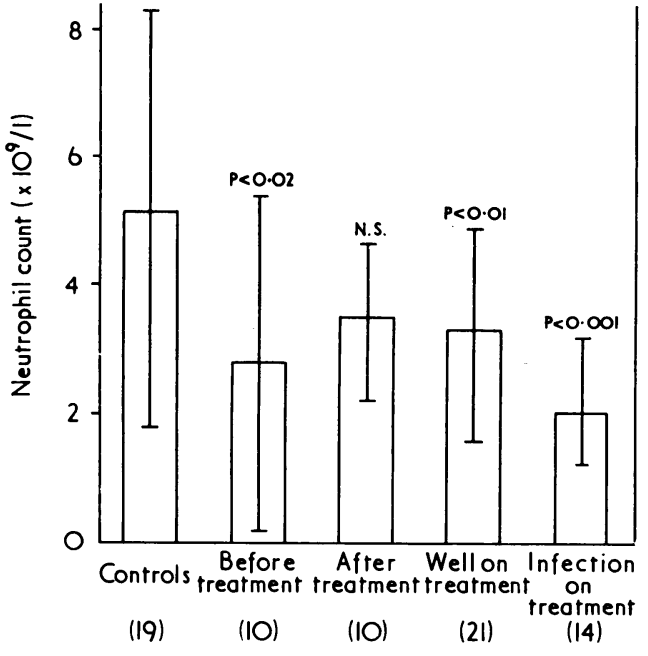

FIG. 4-Neutrophil counts in different groups.

\section{Discussion}

The high infection rate in untreated leukaemia is caused by neutropenia from marrow infiltration, ${ }^{515}$ and neutrophil function may also be impaired. ${ }^{16}$ Most infections in patients in relapse are therefore bacterial, and other aspects of immunity, particularly humoral and cell-mediated responses, are usually normal, ${ }^{1718}$ though diminished cellular immunity has been reported in acute myeloblastic leukaemia. ${ }^{19}$ Severe infections in patients in remission, however, are typically viral, fungal, or protozoal. ${ }^{3} 4$

Since the type of infection differs so greatly a different immunological disturbance is to be expected. Neutropenia was our only significant finding before treatment, in contrast to the lymphopenia, neutropenia, and cellular and humoral immunosuppression of treated patients. Most important were the clear differences between well and infected children in remission "on treatment." Infection was associated with impaired cellmediated immunity and neutrophil and immunoglobulin production. Though the degree and frequency of lymphopenia did not differentiate between well and infected children, it certainly contributed to their low resistance since over half of all treated patients were lymphopenic when tested. All our infected patients had had recent intensive chemotherapy, and none were on nonintensive maintenance therapy, which does not depress cellular immunity. ${ }^{6} 20$

Craniospinal radiotherapy produced more lymphopenia and diminished cellular immunity than cranial or no radiotherapy, though this was not related to the incidence of infection.

Craniospinal radiotherapy carries a significant risk of remission fatalities from opportunistic infection, ${ }^{48}$ and since lymphocyte depletion probably affects mainly $T$-cells ${ }^{821}$ the greater cellular immunosuppression may be due to including thymus as well as more bone marrow in the field irradiated. B-lymphocyte depletion probably contributes to the lymphopenia since over $40 \%$ of our treated patients had one or more immunoglobulin values 3 S.D. below normal, and antibodies against viruses and pooled $E$. coli serotypes were less often present. These findings suggest impaired antibody response rather than less exposure to infection in view of the greater age of the treated children, the frequency of such viral infections during malignant disease, and the positive titres to pooled $E$. coli antigen normally found over the age of 2 years. ${ }^{9}$ Though we found no differences in our few tests of surface immunofluoresecnce, depletion of B-lympho- cytes in treated children has been reported. ${ }^{822}$ Apart from showing humoral immunosuppression our findings indicate a need for caution in interpreting antibody titre results during cytotoxic treatment.

Several patients studied after treatment were still lymphopenic and P.W.M. mitogenic responses were often low, though impaired PHA responses were found only in children on treatment. This variable response to different mitogens ${ }^{2123}$ indicates that more than one lymphocyte subpopulation is involved. All our patients who had low P.W.M. responses after finishing treatment had had craniospinal radiotherapy, so the situation may be analogous to that of two types of PHA-responsive cells-one long-lived and radiosensitive and the other short-lived and chemosensitive. ${ }^{8}$ PHA may be more suitable then P.W.M. for following short-term fluctuations in cellular immunity during treatment.

Hence lowered resistance to infection in malignant disease is multifactorial. The number of lymphocytes is chronically reduced, and several facets of immunity are also weakened during overt infections-namely, neutrophil and immunoglobulin production and cellular immunity as measured by PHA response. Their exact relation to the development of infection could only be established by serial testing throughout the course of the disease since poor immune responses may reflect inhibition or consumption by the infecting agent itself.

What practical use have our findings? The tests in which results were most often abnormal-cell counts, mitogenic responses, immunoglobulins, and antibody titres-can be readily performed, but for such assessments to be useful in patient management clinicians and laboratory workers should collaborate closely and "micro" tests with fewer cells and smaller blood volumes should be performed. Regular immunological evaluation of patients with malignancies is useful when new treatment schedules are under trial, particularly if intensive multiple-agent chemotherapy is used, and in individuals particularly susceptible to infection, since the results of such assessment may guide not only cytotoxic treatment but also the kind of supportive therapy required during overt infections.

We thank Professor J. H. Hutchison and Dr. R. A. Shanks for allowing us to study patients under their care, Dr. R. Sommerville for estimating the virus antibody titres, and Miss C. T. Simms for technical help. We also acknowledge the support of the Higher Medicine Funds of the Western Regional Hospital Board.

\section{References}

1 Pinkel, D., Fournal of the American Medical Association, 1971, 216, 648.

${ }^{2}$ British Medical fournal, 1973, 2, 624

Hughes, W. T., American fournal of Disease in Childhood, 1971, 122, 283.

4 Simone, J. V., Holland, E., and Johnson, W., Blood, 1972, 39, 759.

5 Bodey, G. P., et al., Annals of Internal Medicine, 1966, 64, 328.

Borella, L., and Webster, R. G., Cancer Research, 1971, 31, 420.

7 Hersh, E. M., and Oppenheim, J. J., Cancer Research, 1967, 27, 98.

8 Campbell, A. C., et al., British Medical fournal, 1973, 1, 385.

Webster, A. D. B., Efter, T., and Asherson, G. L., British Medical Fournal, 1974, 3, 16 .

10 Robbins, J. H., et al., Clinical and Experimental Immunology, 1972, 11, 629.

11 Medical Research Council, British Medical fournal, 1973, 2, 381

12 Vowels, M. R., and Willoughby, M. L. N., Archives of Disease in Childhood, $1973,48,436$.

${ }^{13}$ Holland, J. F., and Glidewell, O., New England fournal of Medicine,1972, 287, 769 .

14 Spiers, A. D. S., et al., British Medical fournal, 1974, 3, 77.

15 Hughes, W. T., and Smith, D. R., Cancer, 1973, 31, 1008.

16 Strauss, R. R., et al., Cancer Research, 1970, 30, 480

17 Astaldi, G., et al., Blut, 1972, 24, 153.

18 Borella, L., and Sen, L., Cancer, 1974, 34, 646.

19 Hersh, E. M., and Oppenheim, J. J., Cancer Research, 1967, 27, 98

20 Jones, L. H., et al., British Medical fournal, 1971, 4, 329.

21 Humphrey, G. B., et al., Cancer, 1972, 29, 402.

22 Sen, L., and Borella, L., Cellular Immunology, 1973, 9, 84

23 Green, A. A., and Borella, L., Blood, 1973, 42, 99.

24 Urquhart, G. E. D., Logan, R. W., and Izatt, M. M., fournal of Clinical Pathology, 1971, 24, 736. 